\title{
Aktivitas Dakwah Islam Melalui Kegiatan Liqo dan Dampak terhadap Perilaku Keagamaan Masyarakat Di Kp. Nyalindung Kelurahan Ciumbuleuit Kota Bandung
}

\author{
Siti Aisah*, Komarudin Shaleh
}

Prodi Komunikasi Penyiaran Islam, Fakultas Dakwah, Universitas Islam Bandung, Indonesia.

*Aisyahtaufiqoh2@gmail.com, komarudin_shaleh@yahoo.com

\begin{abstract}
This da'wah is a way to convey the goodness of Islamic teachings to the community. However, the impact felt by the community from the da'wah activities was still lacking in their religious behavior. On this basis, this researcher focuses on "how the Da'wah through Liqo Activities Impacts the Religious Behavior of the Community in Nyalindung Village, Ciumbuleuit Village, Bandung City." This researcher uses descriptive qualitative research, in the data collection process he focuses more on interviews, field observations and the natural atmosphere of the people of Kampung Nyalindung Keluran Ciumbuleuit, Bandung City. With Liqo's activities. This study aims to obtain data about: (1) the purpose of da'wah through Liqo activities in the village of Nyalindung. (2) material presented in Liqo's activities in Nyalindung village. (3) the impact of the religious behavior of the community in the Nyalindung village. The results obtained from this study are: (1) Liqo's activity aims to increase faith in Allah SWT, solve problems of individual life, household life, and social or community problems, form good religious behavior. (2) the material presented in Liqo activities is aiqdah, sharia (fiqih), and morals. (3) the impact of Liqo's activities on the religious behavior of the community, namely a positive impact on the people of Nyalindung village that had left the things of idolatry, obligatory prayers were able to be on time, gradually leaving bad habits in oneself, and increasing knowledge knowledge. The most impactful and felt by society is adding insight and dress ethics for women.
\end{abstract}

Keywords: Da'wah, Impact of Religious Behavior

Abstrak. Dakwah ini menjadi jalan untuk menyampaikan kebaikan ajaran-ajaran islam kepada masyarakat. Namun dampak yang dirasakan masyarakat dari kegiatan dakwah itu masih kurang dalam perilaku keagamaannya. Atas dasar itu peneliti ini berfokus pada "bagaimana Dakwah Melalui Kegiatan Liqo ini Berdampak Terhadap Perilaku Keagamaan Masyarakat di Kampung Nyalindung Kelurahan Ciumbuleuit Kota Bandung." Peneliti ini menggunakan penelitian kualitatif deskriptif, dalam proses pengumpulan data ia lebih menitik beratkan pada wawancara, observasi lapangan dan suasana alamiah terhadap masyarakat Kampung Nyalindung Keluran Ciumbuleuit Kota Bandung. Dengan melalui kegiatan Liqo. Penelitian ini bertujuan untuk memperoleh data tentang: (1) tujuan dakwah melalui kegiatan Liqo di kampung Nyalindung. (2) materi yang disampaikan dalam kegiatan Liqo di kampung Nyalindung. (3) dampak perilaku keagamaan masyarakat di kampung Nyalindung. Hasil yang didapat dari penelitian ini adalah: (1) kegiatan Liqo ini bertujuan meningkatkan keimanan kepada Allah SWT, memecahkan persoalan hidup perseorangan, berumah tangga, dan permasalahan sosial atau masyarakat, membentuk perilaku keagamaan yang baik. (2) materi yang disampaikan dalam kegiatan Liqo merupakan materi aiqdah, syariah (fiqih), dan akhlak. (3) dampak dari kegiatan Liqo terhadap perilaku keagamaan masyarakat yaitu berdampak positif masyarakat kampung Nyalindung sudah meninggalkan hal-hal perbuatan musyrik, shalat wajib sudah bisa tepat waktu, dan menambah wawasan ilmu pengetahuan. Yang paling berdampak dan dirasakan oleh masyarakat yaitu menambah wawasan dan etika berpakaian bagi perumpuan.

Kata Kunci: Dakwah, Dampak Perilaku Keagamaan. 


\section{A. Pendahuluan}

Dakwah merupakan suatu aktivitas yang mulia, menjadi kewajiban bagi setiap umat dengan tujuan untuk memberikan informasi tentang islam dan mengajak orang lain agar bersedia melakukan tindakan tindakan yang mencerminkan nilai nilai islam ( Abd.Rosyadshaleh. 1987. Managemen Dakwah Islam, Jakarta: BulanBintang, hlm. 1). Nilai nilai islam terlihat dari tingkat keimanan masyarakat dan perilaku keagamaannya, mau dilingkungan keluarga, ataupun masyarakat.

Aktivitas dakwah dilakukan dengan mengajak, mendorong, menyeru tanpa tekanan dan atau provokasi serta bukan dengan bujukan dan pemberian barang-barang murahan. Terlalu murah bila iman harus ditukarkan dengan benda-benda atau fasilitas duniawi meski realitas sosial menunjukan kondisi itu. (Bambang S. Ma'arif. 2010,Komunikasi Dakwah (paradigma untuk aksi), Bandung: Simbiosa Rekatama Media, hlm. 30-31.) Aktivitas dakwah ini banyak dilakukan dengan berbagai cara salah satunya yaitu kegiatan dakwah yang bertujuan untuk memenuhi kebutuhan tarbiyah dan memperdalam pengetahuan mengenai islam para kader dakwah dan masyarakat, kegiatan ini dinamakan Liqo. Liqo berarti pertemuan, isinya bisa saja bukan merupakan kajian ilmiyah, tetapi bisa diisi dengan rapat, pertemuan dan musyawarah. Dan dalam kegiatan liqo ini diharapkan akan terbentuknya wawasan dan kepribadian yang islami di lingkungan masyarakat. Istilah liqo di indonesia sering dikaitkan dengan pengajian dalam format kelompok kecil antara lima sampai sepuluh orang. Dimana ada satu orang yang bertindak sebagai narasumber atau yang sering disebut diistilahkan dengan murabbi atau pembina dan komunikan yang disebut mutarabbi. Kegiatan liqo dalam sebuah kelompok bukan hanya bertujuan untuk saling berbagi ilmu agama saja tetapi, juga sebagai ajang memperkuat Ukhuwah islamiyah antar anggota, membentuk kader dakwah dan masyarakat yang berkualitas dalam keagamaan. Liqo mempunyai nilai nilai dakwah islami tersendiri seperti membentuk kepribadian yang lebih baik dalam prilaku dan ajang memperkuat Ukhuwah Islamiah antar anggota atau masyarakat sekitar.

Begitu juga dikampung Nyalindung Rw 09 kelurahan Ciumbuleuit kecamatan Cidadap kota Bandung, terdapat beberapa kelompok liqo, dimana satu kelompok terdiri dari lima sampai 10 orang. Keberadaan liqo di kp. Nyalindung ini menjadi tempat berdakwah menyampaikan ajaran islam dari Aqidah, Fiqih, Akhlak dan ilmu pengetahuan islam atau ilmu pengetahuan umum.

Hal ini ditunjukan dengan masyarakat tergerak untuk mencari ilmu baik dari kalangan remaja, dewasa, dan bahkan lansia. Semenjak mengikuti kegiatan Liqo ini banyak perempuan dikampung tersebut rata rata sudah mau menutup auratnya kalau keluar rumah, asalnya banyak perempuan yang tidak memakai jilbab. Kemudian dulu masih banyak masyarakat yang masih melakukan ritual sesajen dan percaya hal hal mistis namun semua itu kini sudah ditinggalkan dan tidak dilakukan lagi. Berdasarkan uraian diatas penulis hendak meneliti aktivitas dakwah islam melalui kegiatan Liqo di kampung Nyalindung, yang mana kegiatan Liqo tersebut berdampak positif terhadap perilaku masyarakat namun, masih ada masyarakat yang melakukan kebiasaan gibah. Hal ini merupakan perilaku yang tidak terpuji dan dilarang didalam agama islam.

Adapun tujuan penelitian ini adalah:

1. Untuk mengetahui tujuan dakwah islam melalui kegiatan Liqo yang diselenggarakan di kp. Nyalindung Ciumbuleuit

2. Untuk mengetahui materi dakwah islam apa yang disampaikan dalam kegiatan Liqo di kp. Nyalindung Ciumbuleuit

3. Untuk mengetahui dampak aktivitas dakwah islam melalui kegitan Liqo terhadap perilaku keagamaan masyarakat di kp. Nyalindung Ciumbuleuit.

\section{B. Landasan Teori}

\section{Definisi Aktivtas}

Aktivitas adalah keaktifan, kegiatan kegiatan, kesibukan atau bisa juga berarti kerja atau salah satu kegiatan kerja yang dilaksanakan tiap bagian dalam tiap suatu organisasi atau lembaga (Departemen Pendidikan dan Kebudayaan. 1990. Kamus Besar Bahasa Indonesia, Jakarta: Balai Pustaka, Cet ke 3, h.1). 
Menurut Sauel Soeitoe sebenarnya aktivitas bukan hanya sekedar kegiatan bahwa, aktivitas dipandang sebagai usaha mencapai atau memenuhi kebutuhan (Samuel Soeitoe. 1982. Psikologi Pendidikan II, Jakarta: FEUI, hlm. 52)

Dari penjelasan diatas maka dapat disimpulkan bahwa, aktivitas merupakan kegiatan atau keaktifan yang dilakukan baik secara fisik atau non-fisik yang mana mempunyai tujuan dari aktivitas tersebut.

\section{Definisi Dakwah}

1. Pengertian Dakwah

Pengertian Dakwah ditinjau dari sudut etimologi atau bahasa, dakwah berasal dari bahasa Arab, yang berarti panggilan, ajakan, atau seruan. Menurut ilmu tata bahasa Arab, kata dakwah

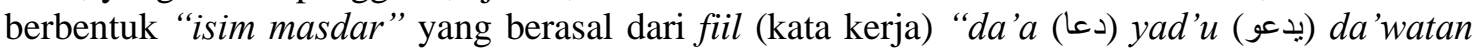
(دعوة) (yang artinya memanggil, mengajak, atau menyeru) (Saputra. 2011. Pengantar Ilmu Dakwah, Jakarta: PT Raja Grafindo Persada, hlm. 1).

Menurut Prof. Toha Yahya Omar, dakwah adalah mengajak manusia dengan cara bijaksana kepada jalan yang benar sesuai dengan perintah tuhan, untuk keselamatan dan kebahagiaan mereka di dunia dan akhirat (Toha Yahya Omar. 2004. Islam dan Dakwah, Jakarta: Zakia Islami Press ,hlm. 67).

Menurut M. Nastsir dakwah adalah ajakan yang berisi amar ma'ruf nahi munkar. Menurutnya, ajakan tersebut tidak cukup dengan lisan saja, melainkan juga dengan bahasa, perbuatan, dan kepribadian mulia secara nyata (Thohir Luth. 1999. M. Natsir, Dakwah dan Pemikirannya, Jakarta: Gema Insani Press, hlm. 80).

Pengertian pengertian para ahli diatas juga menunjukkan bahwa dakwah adalah mengajak manusia baik berbentuk lisan, tulisan, tingkah laku dan sebagainya, yang bertujuan untuk mengenal islam dalam aqidah, syari'ah dan akhlak islamiyah. Semua kegiatan dakwah yang dilakukan merupakan kegiatan yang positif, dengan demikian, dapat dipahami bahwa sebuah ajakan, seruan, ataupun panggilan yang mengarah pada perbuatan yang merusak dan negatif itu tidak termasuk pada arti dari dakwah itu sendiri.

2. Tujuan Dakwah

Tujuan dakwah menurut Masyhur Amin, dibagi menjadi dua bagian yakni tujuan dari segi obyeknya dan tujuan dari segi materinya. Pertama, Tujuan dakwah dari segi obyeknya yaitu:

- Tujuan perorangan, yaitu terbentuknya pribadi muslim yang mempunyai iman yang kuat, perilaku sesuai dengan hukum-hukum yang disyarieatkan Allah SWT dan berakhlak karimah.

- Tujuan untuk keluarga, yakni terbentuknya keluarga bahagia penuh ketentraman dan cinta kasih antara anggota keluarga.

- Tujuan untuk masyarakat, yaitu terbentuknya masyarakat yang sejahtera yang penuh dengan suasana ke-Islaman.

- Tujuan untuk seluruh umat manusia, yaitu terbentuknya masyarakat dunia yang penuh dengan kedamaian dan ketenangan.

Kedua, Tujuan dakwah dari segi materinya yaitu:

- Tujuan akidah, yaitu tentramnya suatu akidah yang mantap di setiap hati seseorang, sehingga keyakinan keyakinan tentang ajaran-ajaran Islam tidak lagi dicampuri dengan keraguan.

- Tujuan hukum, yaitu kepatuhan setiap orang kepada hukum-hukum yang disyari'atkan oleh Allah SWT.

- Tujuan akhlak, yaitu terbentuknya muslim yang berbudi luhur dihiasi dengan sifat sifat yang terpuji dan bersih dari sifat yang tercela. Dari semua tujuan di atas memiliki tujuan akhir yang sama berupa adanya perubahan sikap dan perilaku umat manusia (meliputi orang mukmin maupun orang kafir atau musyrik) yang menunjukkan bahwa umat manusia sudah termotivasi oleh seorang juru dakwah (Masyhur Amin. 1997. Dakwah Islam dan Pesan Moral, Yogyakarta: Al-Amin Pers, hlm. 15). 
Sedangkan M. Natsir menjelaskan tujuan dakwah adalah:

- Memanggil kita kepada syari'at, untuk memecahkan persoalan hidup, baik persoalan hidup perseorangan atau persoalan berumah tangga, berjamaah-bermasyarakat, berbangsa-bersuku bangsa, bernegara, berantarnegara.

- Memanggil kita kepada fungsi hidup kita sebagai hamba allah di atas dunia yang terbentang luas ini, berisikan manusia berbagai jenis, bermacam pola pendirian dan kepercayaan, yakni fungsi sebagai syuhada 'ala an-nas, menjadi pelopor dan pengawas bagi umat manusia.

- Memanggil kita kepada tujuan hidup yang hakiki yakni menyembah Allah. Demikianlah, kita hidup mempunyai fungsi tujuan tertentu (Enjang AS dan Aliyudin. 2009. Dasar Dasar Ilmu Dakwah, Bandung:Widya Padjadjaran, hlm.100).

Dengan demikian tujuan dakwah adalah untuk memperoleh kebahagian dunia dan akhirat. Melakukan proses penyelenggaraan dakwah yang terdiri dalam berbagai aktivitas untuk nilai tertentu, dan nilai yang ingin dicapai oleh keseluruhan usaha dakwah pada hakikatnya merupakan konsekuen logis dari usaha usaha dakwah yang dilakukan dengan sungguh-sungguh. Dan dalam hal tersebut diwujudkan dalam penghayatan, penyebaran dan perubahan atau pembangunan nilai nilai kebaikan dan kebenaran (Syamsuddin. 2016. Pengantar Sosiologi Dakwah, Jakarta: Kencana, hlm. 12).

Allah telah menurunkan wahyu kepada rasulullah dan memerintahkan kepada umat muslim agar bisa menomor satukan seruan atau perintah allah yang mana melakukan ajaran ajaranya dan menjadi jaminan terwujudnya kehidupan yang baik bagi manusia.

3. Materi Dakwah

Materi dakwah adalah ajaran islam itu sendiri, secara umum materi dakwah dapat diklasifikasikan menjadi empat masalah pokok, yaitu:

- Masalah aqidah (keimanan). Masalah pokok yang menjadi materi dakwah adalah akidah islamiah. aspek akidah ini yang akan membentuk moral (akhlak) manusia.

- Masalah Syariah. Materi dakwah yang menyajikan unsur syariat harus dapat menggambarkan atau memberikan informasi yang jelas di bidang hukum dalam bentuk status hukum yang bersifat wajib, mubbah, diannjurkan, makruh, dan haram.

- Masalah Mu'amalah. Islam merupakan agama yang menekankan urusan mu'amalah lebih besar porsinya daripada urusan ibadah. Islam lebih banyak memperhatikan aspek kehidupan sosial daripada aspek kehidupan ritual. Ibadah dalam mu'amalah disini, diartikan sebagai ibadah yang mencangkup hubungan dengan allah dalam rangka mengabdi kepada Allah SWT.

- Masalah Akhlak. Materi akhlak dalam islam adalah mengenal sifat dan kriteria perbuatan manusia serta berbagai kewajiban yang harus dipenuhi. Materi akhlak ini diorientasikan untuk dapat menentukan baik dan buruk, akal, dan kalbu berupaya untuk menemukan standar umum melalui kebiasaan masyarakat. Karena ibadah dalam islam sangat erat kaitannya dengan akhlak (Muhammad Munir dan Wahyu Ilahi. 2006. Manajemen Dakwah, Jakarta: Kencana, hlm. 24-31)

\section{Definisi Liqo}

Kata Liqo berasal dari bahasa arab asal kata (لقي-يلْقى_لقاء) yang artinya bertemu, berjumpa, pertemuan (S. Askar. 2009. Kamus Arab-Indonesia Al-Azhar Terlengkap Mudah \& Praktis, Jakarta Selatan: Senayan Publishing, hlm. 798).

Secara bahasa halaqoh artinya lingkaran dan Liqo artinya pertemuan. Secara istilah Halaqoh berarti pengajian dimana orang orang yang ikut dalam pengajian itu duduk melingkar, dalam bahasa lain disebut juga majlis taklim atau forum yang bersifat ilmiyah. Materinya bisa berkaitan dengan materi tertentu seperti aqidah, fiqih, hadits, sirah dan seterusnya. Sedangkan istilah Liqo lebih umum dari halaqoh karena isinya bisa saja bukan merupakan kajian ilmiah tetapi bisa diisi dengan rapat, pertemuan musyawarah dan seterusnya. Istilah halaqoh dan Liqo di Indonesia umumnya sering dikaitkan dalam kajian format kelompok kecil antara 5 sampai dengan 10 orang, dimana ada satu yang bertindak sebagai narasumber yang sering diistilahkan sebagai murabbi/pembina (http://sirwanto.blogspot.com/2012/12/pengertian-liqo-dan- 
halaqah.html. diunduh 19/11/20 pukul 19.24 Wib). Kegiatan Liqo ini pastinya mempunyai dampak terhadap anggota atau masyarakat yang mengikuti kajian.

\section{Definisi Perilaku Keagamaan}

Perilaku keagamaan terdiri dari dua kata. Yaitu perilaku dan keagamaan. Kata perilaku yaitu berarti tanggapan atau reaksi individu terhadap lingkungannnya. Sedangkan keagamaan yaitu berasal dari kata dasar agama yang berarti sistem, prinsip kepercayaan terhadap tuhan dengan ajaran kebaktian dan kewajiban atas dasar yang diajarkan oleh agama tersebut. Kata keagamaan tersebut mendapatkan awalan "ke" dan akhiran "an" yang mempunyai arrti segala sesuatu yang berkaitan dengan agama (W.J.S Poerwadaminta. 1991. Kamus Besar Bahasa Indonesia Jakarta: PN. Balai Pustaka, hlm. 570).

Djamaludin Ancok dan Fuad Nashori Suroso dalam bukunya yang berjudul "Psikologi Islam, Solusi Islam atas Problem-problem Psikologi" berpendapat bahwa: "aktivitas keagamaan bukan hanya terjadi ketika seseorang melakukan perilaku ritual (beribadah), tapi juga ketika melakukan aktivitas lain yang didorong oleh kekuatan supranatural. Bukan hanya yang berkaitan dengan aktivitas yang tampak dan dapat dilihat mata, tapi juga aktivitas yang tidak tampak dan terjadi dalam diri seseorang". Dengan demikian, aktivitas keagamaan adalah bentuk kegiatan keagamaan yang tidak hanya dalam bentuk ritual, namun juga aktivitas yang tidak tampak, misalnya dzikir dan doa dan lain sebagainya (DJamaluddin Ancok, Fuad Nasori Suroso. 2004. Psikologi Islami, Solusi Islam atas Problem- problem Psikologi, Yogyakarta: Pustaka Pelajar, hlm. 76-81).

Menurut Glock dan Stark terdapat lima dimensi keberagamaan dalam mengkaji ekspresi keberagamaan, yaitu dimensi keyakinan (ideologi), dimensi praktek agama (ritualistik), dimensi penghayatan (experiental), dimensi pengetahuan agama (intelektual), dan dimensi pengalaman (konsekuensial)

1. Dimensi keyakinan (ideologi)

Dimensi keyakinan atau ideologi jika didalam islam aqidah menunjuk pada seberapa tingkat keyakinan muslim terhadap kebenaran ajaran ajaran agamanya, terutama terhadap ajaran ajaran yang bersifat fundamental dan dogmatik. Didalam keberislaman isi dimensi keimanan menyangkut keyakinan tentang allah, surga dan neraka, serta qadha dan qadar.

2. Dimensi praktek agama (ritualistik)

Dimensi keberagamaan yang berkaitan dengan sejumlah perilaku. Yang dimaksud perilaku disini bukanlah perilaku umum yang dipengaruhi keimanan seseorang, melainkan mengacu kepada perilaku perilaku khusus yang ditetapkan oleh agama, seperti tata cara (dalam Islam) ibadah sholat, puasa, zakat, haji, bermuamalah, dan lain sebagainya yang semua ini merupakan ritus-ritus khusus aturan yang wajib ditaati dan dilaksanakan.

3. Dimensi pengetahuan agama (intelektual)

Dimensi pengetahuan agama ini mengacu kepada harapan bahwa orang-orang yang beragama paling tidak memiliki jumlah minimal pengetahuan mengenai dasar-dasar keyakinan, ritus-ritus, Kitab Suci dan tradisi-tradisi yang ada dalam ajaran agamanya.

4. Dimensi pengalaman (konsekuensional)

Dimensi ini menunjukkan akibat ajaran agama dalam perilaku umum, yang tidak secara langsung dan secara khusus ditetapkan agama (seperti dalam dimensi ritualistik). Inilah efek ajaran agama pada perilaku individu dalam kehidupannya sehari-hari. Efek agama ini boleh jadi positif atau negatif, pada tingkat personal dan sosial.

5. Dimensi penghayatan (experiensial)

Dimensi pengalaman ini berkaitan dengan pengalaman keagamaan, perasaan-perasaan, persepsi-persepsi dan sensasi yang dialami seorang pelaku yang melihat komunikasi walaupun kecil, dengan esensi Ketuhanan yakni dengan Tuhan, dan otoritas transendental.

Dimensi ini berkaitan dengan perasaan keagamaan yang dialami oleh penganut agama. Perasaan agama ini dapat bergerak dalam empat tingkatan, yaitu: Responsif (merasa bahwa Tuhan menjawab keluhanya atau kehendaknya), Eskatik (merasakan hubungan yang akrab penuh cinta dengan Tuhan), Konfirmatif (merasakan kehadiran Tuhan atas apa saja yang diamatinya), Partisipatif (merasa menjadi kawan setia, kekasih atau wali Tuhan, menyertai Tuhan dalam 
melakukan karya ilmiahnya) (Jalaluddin Rakhmat. 2004. Psikologi Agama Sebuah Pengantar, Bandung: Mizan, hlm. 93).

Dimensi penghayatan menunjukkan seberapa jauh tingkat seseorang merasakan perasaan-perasaan dan pengalaman-pengalaman religious yang dialami. Sebagai contoh dalam agama Islam dimensi ini terwujud dalam perasaan dekat seorang hamba dengan Allah SWT, merasakan Allah mengabulkan do'a-do'anya, perasaan khusyuk ketika sholat dan berdo'a serta perasaan selalu mendapat peringatan serta pertolongan dari Allah SWT.

\section{Hasil Penelitian dan Pembahasan}

Dengan keadaan masyarakat setempat terutama dalam bidang keagamaan yang terlihat kurang berminat maka muncul kegiatan keagamaan yang lain dengan cara penyampaian dakwah islam yang berbeda yaitu Liqo. Dimana kegitan Liqo ini diadakan dikampung Nyalindung sejak tahun 2005. Pada awalnya kegiatan Liqo ini diadakan karena adanya salah satu murobbi atau pembina kajian Liqo yang tinggal di wilayah $\mathrm{Kp}$. Nyalindung. Merasa miris dengan keadaan masyarakatnya yang sangat jauh dari nilai nilai agama islam terutama dalah hal perilaku keagamaan. Meskipun sudah ada kegiatan keagamaan yang sudah berjalan sejak tahun 1984 namun, tetap saja minat masyarakat terhadap kegiatan tersebut sangat sedikit. Hal itu membuat pembina Liqo tersebut termotivasi dan menemukan cara untuk membangkitkan kembali semangat mengaji atau mencari ilmu masyarakat Kp. Nyalindung yaitu dengan membuka kegiatan Liqo tersebut.

Konsep dari kajian Liqo ini yaitu dibagi menjadi beberapa kelompok, dimana satu kelompok itu terdiri dari pembina kelompok (murobbi) yang sekaligus menjadi pemateri dan memiliki anggota lima bahkan bisa sampai lima belas orang. Dengan penyampaian materi melalui kelompok tentunya diharapkan bisa lebih efektif dan murobbi bisa mengawasi tiap tiap anggotanya dalam hal pelaksanaan ibadah islam. Liqo ini bukan hanya kajian islami dan diskusi biasa saja tetapi didalamnya ada bentuk pembinaan kepribadian seorang muslim secara rutin. Dan ada kenikmatan dalam berukhuwah disana yaitu tingkat silaturahmi antar masyarakat lebih di banyak. Kegiatan Liqo di kampung Nyalindung ini mempunyai kegiatan yang dilakukan secara rutin oleh anggota kelompok kajian dan tentunya tidak lepas dari pengawasan para murabbi. Bentuk kegiatannya yaitu: Pertama, Amalan yaumiyah, Kedua, Setor hafalan Al-Qur'an, Ketiga, Kegiatan KULTUM (Kuliah Tujuh Menit), Keempat, Pelatihan MC (Master of Ceremony).

Kegiatan Liqo di kp. Nyalindung ini menjadi metode atau cara dakwah islam agar masyarakat mau mengikuti kajian dan mengaji. Kegiatan Liqo ini mempunyai beberapa tujuan dan tujuan itu sangatlah penting. Kemudian dengan adanya tujuan itu bisa membuat kita lebih terarah dari apa yang kita lakukan.

Berikut beberapa tujuan dari kegiatan Liqo di kampung Nyalindung Ciumbuleuit. Pertama, adanya Liqo ini untuk menjadi tempat mencari ilmu dan menambah wawasan agama islam. Kedua, meningkatkan keimanan pada diri kita terutama iman kepada allah SWT agar menjadi lebih kuat, kokoh dan tidak gampang terpengaruh. Ketiga, kegiatan Liqo ini bertujuan membentuk karakter masyarakat agar lebih islami. Keempat, kegiatan Liqo ini bertujuan agar masyarakat kampung Nyalindung bisa meningkatkan ibadah kepada Allah SWT. Kelima, dengan adanya kegiatan Liqo ini bertujuan agar memperkuat tali silaturahmi atau Ukhuwah islamiah antar masyarakat. Keenam, dengan adanya kegiatan Liqo bertujuan menjadikan manusia yang lebih baik terutama dalam agama islam. Yang mana awalnya tidak mengenal islam lebih dalam tetapi, dengan adanya kegiatan Liqo ini bisa membuat masyarakat mau memahami agama islam lebih dalam dan mengamalkan ajaran islam dalam kehidupan sehari hari. Karena pada dasarnya ilmu yang didapat akan lebih baik jika kita mengamalkannya baik untuk diri sendiri, keluarga, teman, bahkan masyarakat sekitar.

Materi dakwah yang digunakan dalam kegiatan Liqo pada umumnya mencakup semua aspek dalam islam yang sesuai dengan Al-Qur'an dan Hadits. Tentunya materi yang disampaikan akan disesuaikan dengan kebutuhan masyarakat terlebih dahulu. Seperti materi aqidah, akhlak, syariah (fiqih( dan Liqo juga membahas sejarah-sejarah islam.

Ada beberapa dampak perilaku keagamaan yang dirasakan oleh masyarakat yang mengikuti kegiatan Liqo. Pertama, dampak yang dirasakan oleh masyarakat yang mengikuti kajian Liqo dalam gaya hidup yaitu, bisa membuat lebih sabar dan bersyukur dengan keadaan 
yang sekarang terkadang, kita sibuk membandingkan kehidupan kita dengan orang lain padahal Allah sudah memberi porsi masing-masing kesetiap orang. Kemudian cara berpakaian sudah lebih tertutup dengan menggunakan hijab yang pantas dan sesuai aturan yaitu menutup aurat. Terlihat dari gaya hidup banyak berubah ke hal hal yang lebih baik terutama untuk diri mereka sendiri.

Kedua, dampak yang terlihat dari masyarakat yang mengikuti kegiatan Liqo ini yaitu dampak dalam ibadah. Karena memiliki amalan harian yang harus dilaksanakan maka masyarakat lebih giat untuk menghafal surat-surat dalam Al-Quran meskipun setoran hafalan dilakukan sedikit demi sedikit dan juag belajar tahsin untuk membenarkan tajwid dan cara bacanya. Kemudian masyarakat merasakan termotivasi untuk melakukan ibadah yang biasanya leha-leha dalam beribadah kini ibadahnya sudah lebih meningkat.

Ketiga, dampak kegiatan Liqo ini dalam lingkungan keluarga yang mengikuti kegiatan Liqo yaitu, amalan harian yang dilakukan oleh orang tuanya itu bisa diterapkan kepada anak anaknya. Seperti menghafal Al-Quran, tadarus, dan juga mengajarkan anak tentang etika yang baik bagaimana bersikap kepada orang tua, orang lain. Meskipun sulit mengotrol perilaku anakanak tetapi para orang tua tidak menyerah untuk mengajarkan hal yang baik. kemudian seorang istri dalam rumah tangga lebih mengetahui bagaimana perilaku yang baik kepada suami, dan berusaha menjadi istri yang shalihah dengan tidak membantah suami selagi itu hal yang baik dan bisa dilakukan.

Keempat, dampak kegiatan Liqo ini dalam lingkungan sosial yaitu, adanya rasa toleransi dan saling menghargai antar masyarakat kampung Nyalindung.

Menjalin sialturahmi atau ukhuwah islamiah ini juga dirasakan masyarakat dan terlihat memang berusaha menjaga hubungan baik antar masyarakat. Awalnya ada masyarakat yang tidak saling mengenal satu sama lain padahal mereka satu kampung dan karena mengikuti kegiatan Liqo ini mereka jadi saling mengenal satu sama lain.

Sesuai dengan teori, masyarakat kampung Nyalindung mempelajari materi tentang keimanan atau aqidah dan dilihat dari lingkungan bahwa masyarakat tentunya beriman kepada allah SWT. Sesuai dengan rukun iman yang wajib diimani seluruh umat muslim. Dengan bukti bahwa masyarakat kampung Nyalindung sudah meninggalkan hal-hal yang berbau musyrik seperti sesajen yang pernah dilakukan dulu. Meyakini terhadap kebenaran ajaran ajaran islam ini tentunya masyarakat kampung Nyalindung yakin dengan menjalankan apa yang diperintah Allah, dan menjauhi apa yang dilarang oleh Allah SWT.

Tingkat kepatuhan masyarakat yang mengikuti kajian Liqo meningkat dengan adanya mau keinginan untuk melakukanya dan mengikuti amalan amalan yang sudah didapatkan ilmunya. Seperti shalat tepat waktu, puasa bukan hanya yang wajib di bulan ramadhan saja tetapi sudah mau melakukan puasa sunnah meskipun belum menjadi kebiasaan, kepatuhan masyarakat ini sudah mulai terbentuk meskipun belum ada konsisten dalam melaksanakan beribadah.

Dengan pengetahuan yang bertambah masyarakat sudah bisa merubah kebiasaan yang buruk menjadi baik minimal untuk dirina sendiri. Seperti saling talong menolong, menegakkan keadilan dan kebenaran, berlaku jujur, memaafkan, menjaga lingkungan hidup dengan adanya kerja bakti membersihkan lingkungan, menjaga amanat, tidak mencuri, dan mematuhi normanorma islam dalam berperilaku. Meskipun, belum bisa sepenuhnya meninggalkan kebiasaan buruk tetapi masih bisa dirubah terus menerus menjadi baik atau perbuatan tidak baik itu sampai ditinggalkan. 


\section{Kesimpulan}

Tujuan kegiatan Liqo yaitu, meningkatkan keimanan kepada allah, memecahkan persoalan hidup dari perseorangan, persoalan berumah tangga, dan permasalahan sosial. Saling mengingatkan tentang kebaikan satu sama lain. Kemudian Terlihat bahwa tujuan dakwah melalui kegiatan Liqo untuk membentuk perilaku yang baik terhadap masyarakat dan dilakukan secara bertahap.

Materi yang disampaikan dala kegiatan Liqo yaitu, Kegiatan Liqo ini mempunyai beberapa materi yang sesuai dengan teori materi dakwah islam, yaitu; aqidah akhlak, syariah (fiqih), dan ilmu pengetahuan umum.

Dampak kegiatan Liqo terhadap perilaku keagamaan masyarakat di kampung Nyalindung berdampak positif meliputi keyakinan atau aqidah yaitu, masyarakat kampung Nyalindung sudah meninggalkan hal-hal perbuatan musyrik seperti sesajen yang pernah dilakukan dulu. Kemudian praktek agama, seperti shalat tepat waktu, puasa bukan hanya yang wajib di bulan ramadhan saja tetapi sudah mau melakukan puasa sunnah. Meskipun belum menjadi kebiasaan, kepatuhan masyarakat ini sudah mulai terbentuk. Dari pengalaman atau akhlaknya yaitu, belum bisa sepenuhnya meninggalkan kebiasaan buruk tetapi masih bisa dirubah terus menerus menjadi baik. dalam pengetahuan agamanya yaitu, kegiatan Liqo ini menambah wawasan ilmu pengetahuan msyarakat terutama dalam ilmu agama islam. Dan dalam penghayatan (experensial) yaitu, mereka merasakan bahwa allah itu dekat dengan begitu untuk melakukan dosa atau meninggalkan shalat saja sudah merasa takut kepada Allah SWT.

\section{Daftar Pustaka}

Abd.Rosyadshaleh. 1987. Managemen Dakwah Islam, Jakarta: BulanBintang, hlm. 1

Samuel Soeitoe. 1982. Psikologi Pendidikan II, Jakarta: FEUI, hlm. 52

Departemen Pendidikan dan Kebudayaan. 1990. Kamus Besar Bahasa Indonesia, Jakarta: Balai Pustaka, Cet ke 3, h.1

Saputra. 2011. Pengantar Ilmu Dakwah, Jakarta: PT Raja Grafindo Persada, hlm. 1

Masyhur Amin. 1997. Dakwah Islam dan Pesan Moral, Yogyakarta: Al-Amin Pers, hlm. 15

Muhammad Munir dan Wahyu Ilahi. 2006. Manajemen Dakwah, Jakarta: Kencana, hlm. 24-31

DJamaluddin Ancok, Fuad Nasori Suroso. 2004. Psikologi Islami, Solusi Islam atas Problemproblem Psikologi, Yogyakarta: Pustaka Pelajar, hlm. 76-81

Bambang S. Ma'arif. 2010,Komunikasi Dakwah (paradigma untuk aksi), Bandung: Simbiosa Rekatama Media, hlm. 30-31 